\title{
Characterization of Multipotent Adult Progenitor Cells, a Subpopulation of Mesenchymal Stem Cells
}

\author{
MORAYMA REYES AND CATHERINE M. VERFAILLIE \\ Stem Cell Institute and Department of Medicine, University of Minnesota, \\ Minneapolis, Minnesota 55455, USA
}

\begin{abstract}
Mesenchymal stem cells were isolated and a subpopulation of cells-multipotent adult progenitor cells-were identified that have the potential for multilineage differentiation. Their ability to engraft and differentiate in vivo is under investigation.
\end{abstract}

Keywords: Autologous stem cells; Mesenchymal stem cells; Progenitor cells

Stem cells are cells with substantial proliferation potential that can differentiate into several cell lineages. Over the last 10 to 20 years, stem cells have been identified for almost all organs. The most extensively characterized are hematopoietic stem cells (HSCs), ${ }^{1}$ whereas neural stem cells (NSCs),${ }^{2-4}$ gastrointestinal stem cells, ${ }^{5}$ epidermal stem cells, ${ }^{6}$ hepatic oval cells, ${ }^{7}$ and mesenchymal stem cells $(\mathrm{MSCs})^{8-11}$ have been more recently described. Embryonal stem cells (ESs) ${ }^{12-14}$ are the quintessential stem cell: they have unlimited self-renewal and multipotent differentiation potential. Compared with ES cells, tissue-specific stem cells have less self-renewal ability and, although they differentiate into multiple lineages, they are not multipotent. During the last 3-4 years, a number of studies have shown that tissue-specific stem cells may have the ability to generate cells of tissues from unrelated organs. ${ }^{15-22}$ Whether this constitutes "plasticity" or "transdifferentiation," or whether a small population of multipotent potent stem cells persists in postnatal tissues is not known. However, that stem cells exist in postnatal tissues with previously unknown proliferation and differentiation potential opens up the possibility of using autologous stem cells to treat otherwise incurable degenerative, traumatic, or congenital diseases. In addition to the obvious immunological advantage of using autologous stem cells, these cells are also not encumbered by ethical considerations. However, very little is known concerning the phenotype and genotype of multipotent postnatal stem cells, their role in vivo, or their engraftment and differentiation potential after transplantation.

Address for correspondence: Catherine M. Verfaillie, M.D., Professor of Medicine, Box 806 UMHC, 420 Delaware Street, S.E., Minneapolis, Minnesota 55455. Voice: 612-624-3921; fax: 612-626-4074

verfa001@tc.umn.edu 
Fridenshtein ${ }^{23}$ was the first to identify a fibroblast-like cell in the bone marrow that can be cultured undifferentiated in vitro and can differentiate in mesenchymal cell types in vitro and in vivo. He named this cell a fibroblast-colony-forming cell. Since then, Caplan ${ }^{8}$ and later Prockop ${ }^{24}$ and Simmons ${ }^{25}$ have purified, expanded, and characterized cells in marrow that they termed "mesenchymal stem cells" or MSCs. These cells can be found in rat, baboon, some mouse strains, and human marrow and can be induced to differentiate to osteoblasts, chondroblasts, adipocytes, fibroblasts, and, at least in rodents, skeletal muscle.

We isolated mesenchymal cells by depleting $\mathrm{CD}_{4} 5^{+}$cells and glycophorin- $\mathrm{A}^{+}$ cells from marrow and culture expansion of the population in serum-low or serumfree culture conditions with EGF and PDGF-BB. Within this population of cells, we have identified a subpopulation of cells we termed Multipotent Adult Progenitor Cells, or MAPCs, as they can be cultured for at least 70 cell doublings, have long telomeres that do not shorten in culture, and have multilineage differentiation potential. Indeed, MAPCs differentiate under specific culture conditions to mesenchymal cell types (cartilage, bone, fibroblasts and adipocytes) as well to cells of almost all other mesodermal cell lineages (skeletal, smooth and cardiac myoblasts and von Willebrand factor-positive endothelial cells). In addition we have evidence that MAPCs can be induced to differentiate to cells of the neuroectodermal lineage, including beta-tubulin-III, neurofilament, neuron-specific enolase and glutamate-positive neurons, glial fibrillar acidic protein-positive astrocytes and myelin-basic protein and galactocerebroside-positive oligodendrocytes. Differentiation to all lineages was shown by presence of multiple markers for these lineages by immunohistochemistry and Western blot. The ability of MAPCs to perform normal physiological functions in vitro is being examined. Whether MAPCs will engraft in vivo and differentiate into tissue-pecific cells in vivo is currently being evaluated. Finally, although MAPCs can be subcloned at 10 cells per well, we have not been able to initiate cultures with a single MAPC. Retroviral gene marking is therefore being used to demonstrate that a single marrow-derived MAPC can differentiate into all lineages.

Since these cells may also be present in marrow of mice and rat, we hypothesize that very rare cells exist in marrow that have extensive proliferation potential and can differentiate in tissue-specific cells different from the organ from which they are derived. We believe that such MAPCs may be multipotent descendants from primordial germ cells, whose function in vivo is still unknown.

\section{ACKNOWLEDGMENTS}

This work was supported in part by a grant from the NIH to M.R., the Children's Cancer Research Fund, and Fairview-University of Minnesota.

\section{REFERENCES}

1. Weissman, I.L. 2000. Translating stem and progenitor cell biology to the clinic: barriers and opportunities. Science 287: 1442-1446.

2. GAGE, F.H. 2000. Mammalian neural stem cells. Science 287: 1433-1438. 
3. Svendsen, C.N., M.A. Caldwell \& T. Ostenfeld. 1999. Human neural stem cells: Isolation, expansion and transplantation. Brain Pathol. 9: 499-513.

4. OKabe, S., K. Forsberg-Nilsson, A.C. Spiro, et al. 1996. Development of neuronal precursor cells and functional postmitotic neurons from embryonic stem cells in vitro. Mech. Dev. 59: 89-102.

5. Potten, C. 1998. Stem cells in gastrointestinal epithelium: numbers, characteristics and death. Phil. Trans. R. Soc. Lond. B Biol. Sci. 353: 821-830.

6. Watt, F. 1997. Epidermal stem cells: markers patterning and the control of stem cell fate. Phil. Trans. R. Soc. Lond. B Biol. Sci. 353: 831.

7. Alison, M. \& C. Sarraf. 1998. Hepatic stem cells. J. Hepatol. 29: 678-683.

8. Haynesworth, S.E., M.A. Barber \& I.A. Caplan. 1992. Cell surface antigens on human marrow-derived mesenchymal cells are detected by monoclonal antibodies. Bone 13: $69-80$.

9. Pittenger, M.F., A.M. Mackay, S.C. Beck, et al. 1999. Multilineage potential of adult human mesenchymal stem cells. Science 284: 143-147.

10. Gronthos, S., A.C. Zannettino, S. Graves, et al. 1999. Differential cell surface expression of the STRO-1 and alkaline phosphatase antigens on discrete developmental stages in primary cultures of human bone cells. J. Bone Min. Res. 14: 47-56.

11. Prockop, D. 1997. Marrow stromal cells as stem cells for nonhematopoietic tissues. Science 276: 71-74.

12. Shamblott, M., J. Axelman, S. Wang, et al. 1998. Derivation of pluripotent stem cells from cultured human primordial germ cells. Proc. Natl. Acad. Sci. USA 95: 13726-13731.

13. Thomson, J.A., J. Itskovitz-Eldor, S.S. Shapiro, et al. 1998. Embryonic stem cell lines derived from human blastocysts. Science 282: 114-114.

14. Reubinoff, B.E., M.F. Pera, C.Y. Fong, et al. 2000. Embryonic stem cell lines from human blastocysts: somatic differentiation in vitro. Nat. Biotech. 18: 399-404.

15. JACKSON, K., T. Mi \& M.A. Goodell. 1999. Hematopoietic potential of stem cells isolated from murine skeletal muscle. Proc. Natl. Acad. Sci. USA 96: 14482-14486.

16. Ferrari, G., G. Cusella-De Angelis, M. Coletta, et al. 1998. Muscle regeneration by bone marrow-derived myogenic progenitors. Science 279: 528-530.

17. Gussoni, E., Y. Soneoka, C. Strickland, et al. 1999. Dystrophin expression in the mdx mouse restored by stem cell transplantation. Nature 401: 390-394.

18. Asahara, T., H. Masuda, T. TAKAhashi, et al. 1999. Bone marrow origin of endothelial progenitor cells responsible for postnatal vasculogenesis in physiological and pathological neovascularization. Circ. Res. 85: 221-228.

19. Lin, Y., D.J. Weisdorf, A. Solovey, et al. 2000. Origins of circulating endothelial cells and endothelial outgrowth from blood. J. Clin. Invest. 105: 71-77.

20. Petersen, B.E., W.C. Bowen, K.D. Patrene, et al. 1999. Bone marrow as a potential source of hepatic oval cells. Science 284: 1168-1170.

21. Theise, N.D., S. BADVE, R. SAXENA, et al. 2000. Derivation of hepatocytes from bone marrow cells in mice after radiation-induced myeloablation. Hepatology 31: 235-240.

22. Theise, N.D., M. Nimmakayalu, R. Gardner, et al. 2000. Liver from bone marrow in humans. Hepatology 32: 11-16.

23. Fridenshtein, A. 1982. Stromal bone marrow cells and the hematopoietic microenvironment. Arkh. Patol. 44: 3-11.

24. Colter, D.C., R. Class, C.M. DiGirolamo \& D.J. Prockop. 2000. Rapid expansion of recycling stem cells in cultures of plastic-adherent cells from human bone marrow. Proc.Natl. Acad. Sci. USA. 97: 3213-3218.

25. Gronthos, S. \& P. Simmons. 1996. The biology and application of human bone marrow stromal cell precursors. J. Hematol. 5: 15.

\section{DISCUSSION}

I. LemischKa (Princeton University, Princeton, $N J$ ): Is it possible that these cells are very rare? What would you estimate their frequency to be? 
Verfaillie: 1 in $10^{7}$ or 1 in $10^{8}$.

LEMISCHKA: Is it possible that these cells actually don't exist in bone marrow at all? but it is a phenomenon where... after all, we have Dolly ... you can re-program all nuclei? Is it possible that what we are really looking at here is something that may be happening at some very low frequency during the culture period? In that case, it doesn't make the cells any less neat and potentially useful, but it does put to rest any speculation about whether they may be functional in the well-being of the human or the mouse.

VERfAILLIE: That may be possible. We really need a better selection method up front rather than having to wait for 30 or so doublings before we have a cell population that is homogenous. We are working on trying to make antibodies.

G. Keller (Mt. Sinai School of Medicine, New York, NY): Can you reproducibly generate such cell lines?

VERFAILLIE: That is correct. We have generated the multipotent cells from at least 50 human donors.

KELLER: Have you tried to inject these cells into SCID mice and get teratomas?

VERFAILLIE: We have injected early-passage cells into SCID mice and have not seen teratomas. We actually have to go back and take a much more homogenous population.

KELLER: You would like to go for the ones that are starting to express OCT4, for instance?

VERFAILliE: We have not done those. We have not waited 40 or so doublings and injected them, but we need to do that.

H.-J. BÜHRING (Eberhard Karls University, Tübingen, Germany): How do you separate the mesenchymal stem cells from the multipotent adults? What are the results?

Verfaillie: We subclone so we have cells that grow for extensive periods of time. If we induce differentiation to the neuronal lineage during the first 20 or so doublings, $77 \%$ of the cells die. When we wait until beyond passage 40, the vast majority differentiates. We have no way of purifying by cell surface markers.

M.A.S. Moore (Memorial Sloan-Kettering Cancer Center, New York, NY): The stabilization of telomeres and the upregulation of telomerase is a very exciting feature of these cells. Could you use that-telomerase-positive selection- early on? There is an antibody — not a very good one-but then you would have to immobilize your cells.

VERFAILLIE: We have thought about using progenitor constructs to select for such positive cells. We are in the process of generating some now.

C.J. EAves (Terry Fox Laboratory, Vancouver, B.C., Canada): Have you tried to isolate these cells from any other species?

VERFAILliE: We actually started the work in mouse, and there are some very peculiar differences between mouse and human, but we can generate the cells from C57BL/6 mice. We have tried CD45 cells and plate them right away-they do not want to grow. If you let them grow in vitro for 2 weeks with some of the hematopoietic cells, then CD45 cells and plate them, then it works. They require LIF, which is interesting because mouse ES cells also require LIF, whereas human ES cells do not require LIF. Again in the mouse system we see Oct-4 increase over time. We just started to look at the rat.

EAvES: So what is the frequency because one in $10^{7}$ to $10^{8}$ would be a little demanding in the mouse? 
Verfaillie: We have no idea what the frequency is in the mouse. We used five mice and grew them out at 10 cells per well from the five mice. We actually had six or seven populations grow out. I do not know at this point what the frequency would be.

Y. REISNER (The Weizmann Institute of Science, Rehovot, Israel): Have you looked at the immune response against these cells?

VERFAILLIE: No, we have not looked at it, although several people at our institution will start doing that.

Simmons: Can you give us some idea of the yields in this enrichment procedure? It has been our experience that if you negatively select for these cells, you lose a lot, which is the reason why it is so difficult to negatively select for these cells by depletion of $\mathrm{CD} 45^{+}$cells in mouse. As Paul Kincaid showed many years ago, there is very tight association between stromal elements and developing hematopoietic cells within the bone marrow of mice. That is what we are dealing with. These associations are very hard to disrupt and it has been our experience that we have to treat the marrow preparations with EDTA to physically disrupt them. Even after this you still lose a very high proportion because you are removing $\mathrm{CD} 45^{+}$cells that are in turn bound onto them. So what is your yield?

VERFAILliE: For human bone marrow, I have numbers for you-about 1 in 5000. The ones that grew out are another 1 in 5000, so close to 1 in a million. There are a lot of culture steps in between and a lot of selections so the number may not be correct but 1 in $10^{-8}$ may be the frequency.

EAVES: Because the cells have gone through so many divisions, have you created a cell line? Is what you are seeing an artifact of a cell line?

VERFAILlie: The only answer I can give you for that is that if we look at 50 cell doublings or 30 cell doublings we can still induce the same differentiation. If you let them become confluent, they stop growing. They do not behave as truly malignant.

EAVES: Have you looked for mutations that may be present?

VERFAILliE: Yes. We have not looked at Ras mutations or any other potential oncogenes to find out whether there are mutations in any of them.

EAvES: Nevertheless, this is very interesting. 